\title{
Anterior Discectomy and Fusion versus Posterior Foraminotomy in Treatment of Cervical Radiculopathy: A Comparative Prospective Study
}

\author{
Ahmad Abdalla ${ }^{(0)}$, Ali A. Abd Elaleem \\ Neurosurgery Department, Assiut University, Assuit, Egypt \\ Email: pcahmadabdalla@yahoo.com
}

How to cite this paper: Abdalla, A. and Elaleem, A.A.A. (2019) Anterior Discectomy and Fusion versus Posterior Foraminotomy in Treatment of Cervical Radiculopathy: A Comparative Prospective Study. Open Journal of Modern Neurosurgery, 9 , 441-451.

https://doi.org/10.4236/ojmn.2019.94042

Received: September 30, 2019

Accepted: October 15, 2019

Published: October 18, 2019

Copyright $\odot 2019$ by author(s) and Scientific Research Publishing Inc. This work is licensed under the Creative Commons Attribution International License (CC BY 4.0).

http://creativecommons.org/licenses/by/4.0/

\section{Abstract}

Introduction: Cervical radiculopathy is caused by either cervical disc herniation or bone spurs due to cervical spine degeneration. It is common in middle aged and elderly patients. Those patients who are refractory to conservative treatment are candidates for surgical management. The surgical approaches for cervical radiculopathy are either anterior cervical discectomy and fusion (ACDF) or posterior cervical foraminotomy (PCF). In spite of many reports on ACDF and PCF, only a few studies directly compare the outcomes of both techniques. Purpose: To compare anterior cervical discectomy and fusion (ACDF) with posterior cervical foraminotomy (PCF) for the treatment of cervical radiculopathy, regarding the surgical, clinical and radiological outcomes. Patient and methods: This is a prospective randomized controlled clinical study carried on 44 patients with unilateral cervical radiculopathy. They are divided into 2 groups; group (A) included 23 patients who underwent ACDF and group (B) included 21 patients who underwent PCF, with 1 year follow up. The patient age, sex, clinical manifestations, surgical outcomes as number of cervical level, operative time, blood loss, complications and length of hospital stay were recorded. Visual analogus scale (VAS) and neck disability index (NDI) were used for evaluation of clinical outcomes. Postoperative imaging was done after 1 year to detect instability or adjacent level degeneration. Chi-square and unpaired T-test were used to compare the mean values of both groups. Results: The mean age was nearly 45 years for both groups. C5-6 ACDF was the most common level in group (A), while C6-7 PCF was the most frequent operated level in group (B). PCF group had less operative time, blood loss and length of hospital stay than ACDF group. Clinical improvement of the mean values of VAS and NDI were more pro- 
nounced in PCF group as compared to ACDF group with statistically significant difference. No cases of cervical instability were recorded during the period of follow up. Conclusion: Posterior cervical foraminotomy is a safe and effective technique for the treatment of cervical radiculopathy as compared to anterior cervical discectomy and fusion. PCF has a shorter operative time, less hospital stay and better clinical outcome.

\section{Keywords}

Cervical Radiculopathy, Anterior Cervical Discectomy and Fusion, Posterior Cervical Foraminotomy

\section{Introduction}

Cervical radiculopathy is caused by either cervical disc herniation or bone spurs due to cervical spine degeneration. It is common in middle-aged and elderly patients. Symptoms depend on which nerve root is compressed; including neck and arm pain, numbness, paresthesia and motor weakness. Most of patients can be treated by conservative measures including anti-inflammatory medications, neck collar, physical therapy and epidural steroid injections. But those patients who are refractory to conservative treatment are candidates for surgical management [1].

The surgical approaches for cervical radiculopathy are either anterior or posterior. The anterior cervical discectomy and fusion (ACDF) was the gold standard line of treatment for cervical disc disease since Smith and Robinson description in 1958. Although there are good results of ACDF, many disadvantages were recorded including the risk of injury of important structures such as the esophagus, carotid arteries and the recurrent laryngeal nerve. Also, adjacent segment disease progression was noticed [2].

Posterior Cervical Foraminotomy (PCF) is considered as an effective procedure and alternative technique to $\mathrm{ACDF}$ for the treatment of cervical radiculopathy. It provides direct nerve root decompression and maintains the cervical mobility by avoiding fusion of the spinal segment. Also, it avoids the approach-related complications of ACDF [3]. In spite of many reports on ACDF and PCF, only a few studies directly compare the outcomes of both techniques.

\section{Aim of the Work}

It is to compare anterior cervical discectomy and fusion and Posterior cervical foramintomy in treatment of cervical radiculopathy; regarding the surgical, clinical and radiological outcomes.

\section{Patients and Methods}

This is a prospective randomized clinical trial conducted upon 44 patients complaining of unilateral cervical radiculopathy, during the period from January 
2017 to June 2019. The patients were divided into 2 groups; group (A) include 23 patients underwent anterior cervical discectomy and fusion (ACDF), while group (B) include 21 patients underwent posterior cervical foraminatomy. All patients signed an informed consent, and this study has been approved by the Ethical Committee.

\subsection{Inclusion Criteria}

1) Age range from 20 to 60 years of both sexes.

2) Denovo unilateral cervical radiculopathy due to either disc or bone spur.

3) Failure of all conservative measures for 3 months.

4) One or two level pathology.

\subsection{Exclusion Criteria}

1) Central disc prolapse.

2) Cervical instability.

3) Previous cervical spine surgery.

4) Three or more level affection.

\subsection{Preoperative Evaluation}

All patients were subjected to full history taking (age, sex, comorbidities as smoking, hypertension and diabetes, duration of symptoms and main complain either neck pain and/or brachialgia), general and neurological examination (spurling sign, sensory affection, motor weakness and reflexes).

Basal laboratory investigations (complete blood picture, prothrombin time and concentration, urea and creatinine), plain $\mathrm{x}$-ray of the cervical spine with flexion and extension views (to detect instability) and MRI of the cervical spine (to evaluate the levels and direction of compression) were done for all patients.

\subsection{Surgical Techniques}

\section{1) Anterior cervical discectomy and fusion}

The discectomy was performed as routine under general anesthesia through a transverse incision. Either the remaining disc or the bone osteophytes were removed with a curved angled curette and high speeddrill with a diamond burr. The dura was visualized after transection of the posterior longitudinal ligament. A synthetic peek cage graft was inserted after discectomy and confirmed at the correct position and level by using c-arm fluoroscopy.

\section{2) Posterior cervical foraminotomy}

When the lamino-facet junction was identified, a small lamino foraminotomy was done using kerrison rongeurs or a drill, allowing visualization of the lateral border of the dura and exit nerve root. A nerve hook was used to palpate the foramen to identify any disc fragment or osteophytes. A No. 11 blade and forceps were used to remove the disc, while down angled curettes ware used to remove ventral osteophytes. 
Postoperatively, all patients received analgesics and antibiotics. They were followed up clinically and radiological for 12 months in the outpatient clinic.

\subsection{Outcome Measures}

1) Surgical outcomes including the cervical levels operated upon, operative time, blood loss and length of hospital stay were recorded. Also, intraoperative and postoperative complications as dural tear and CSF leak, root injury, soft tissue, vascular injury, neurological deficit, wound hematoma, infections and cage failure were recorded.

2) Clinical outcomes were evaluated by neck disability index (NDI) and visual analogue scale (VAS) after first day postoperatively, 3 months, 6 months and 1 year.

3) Radiological assessments by plain $x$-ray with dynamic views were done regularly at 6 months and 1 year follows up, to assess fusion rate after ACDF and detect any instability after both procedures. MRI of the cervical spine was requested when recurrent symptoms or suspicious of adjacent level stenosis was present. $\mathrm{Pa}$ tients need re-operation at the same level or adjacent levels were recorded.

\subsection{Statistics}

Mean \pm standard deviation, range, percentage, fisher test, student unpaired $t$-test and chi-square test were used to analyze the data of this study.

\section{Results}

Ages in the ACDF group ranged from 30 to 60 years (mean 45.4 years), while the PCF patients ranged from 27 to 55 years (mean 44.6 years). The ACDF group had 13 males and 10 females, and the PCF group contained 10 males and 11 females. C5-6 ACDF was the most common level in group (A), while C6-7 PCF was the most frequent operated level in group (B). As regards the number of levels; single level surgery was more common than double level surgery in both groups. All previous data are summarized in Table 1.

There was a statistically significant difference between both groups as regard operative time, blood loss and length of hospital stay as shown in Table 2.

One patient in each group had intraoperative unintended dural tear, where gel foam and fibrin glue were used and no CSF leak occurred. No other intra operative or postoperative complications as shown in Table 2 were recorded.

The clinical improvement of neck pain and brachialgia were more pronounced in PCF group as compared to ACDF group. The mean values of VAS and NDI showed that there was statistically significant difference between the two groups, as shown in Table 3 and Figure 1 and Figure 2.

Follow up plain $\mathrm{x}$-ray with flexion-extension views were done for all patients after 1 year of the operation and showed no signs of cervical instability for both group. No symptoms of recurrence, adjacent level stenosis and reoperations were recorded in our study. 


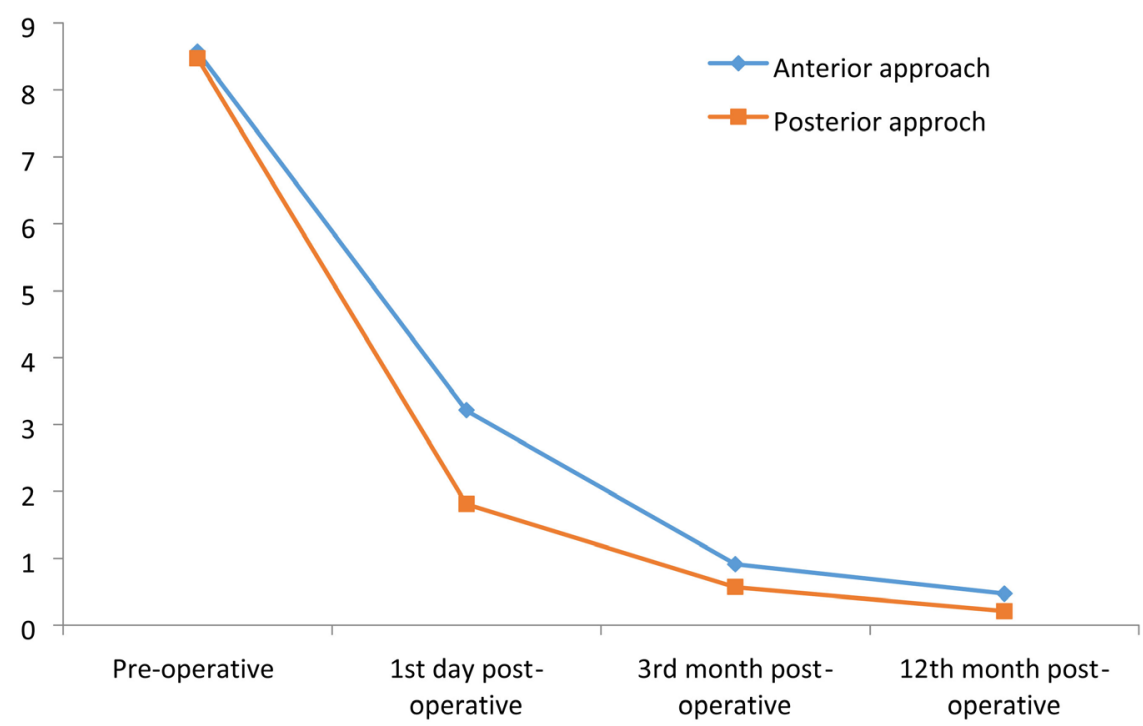

Figure 1. Change in VAS in both approaches in the current study.

Table 1. Patient's characteristics.

ACDF group (A) PCF group (B)

Age (years):

- Range

$30-60$

$27-55$

- $\quad$ Mean \pm SD

$45.47 \pm 8.23$

$44.66 \pm 9.09$

Sex

Male:Female

13:10

Side of radiculopathy:

Right:Left

$10: 13$

10:11

Comorbidities:

Smoking:

Hypertension:

Diabetes:

Number of levels: (No, \%)

- Single level

- Double level

Operated levels: (No, \%)

- $\mathrm{C} 3,4$

- $\mathrm{C} 4,5$

- $\mathrm{C} 5,6$

- $\mathrm{C} 6,7$
13

10

1

1

2

0

$20(87 \%)$

$17(81 \%)$

$3(13 \%)$

$4(19 \%)$

$(11.5 \%)$

$4(16 \%)$

$9(34.6 \%)$

(24\%)

$12(46.1 \%)$

(28\%)

$2(7.8 \%)$ 


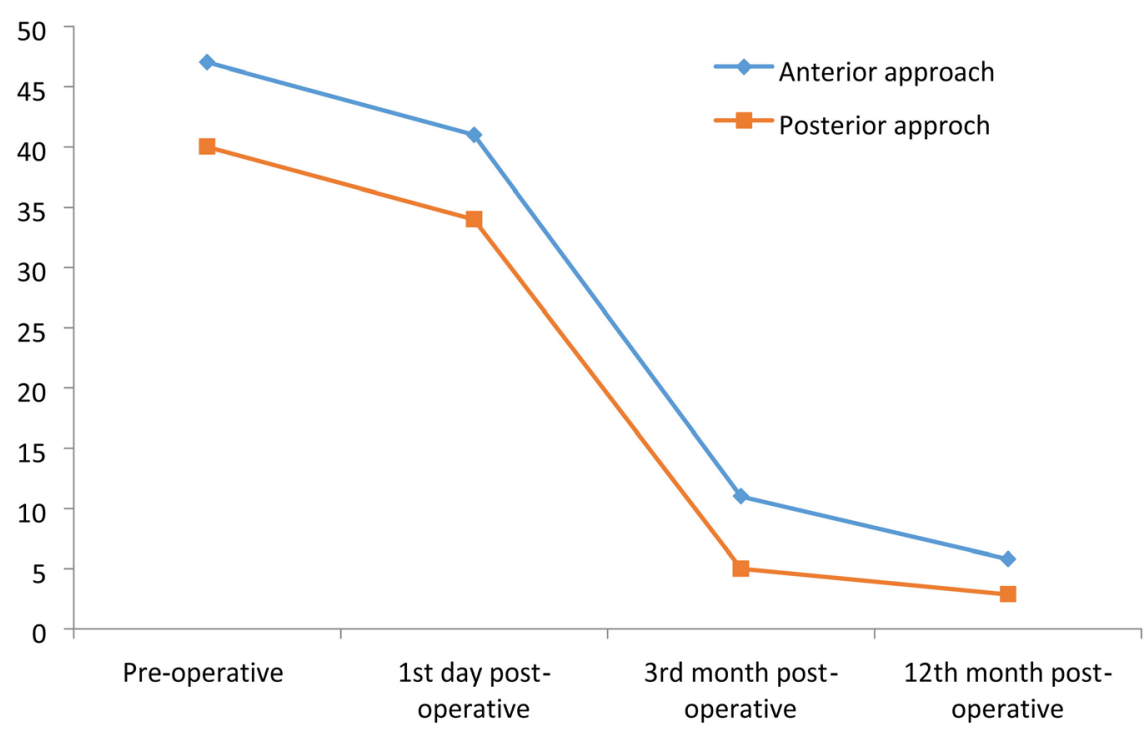

Figure 2. Change in NDI in both approaches in the current study.

Table 2. Surgical outcomes.

ACDF group (A) PCF group (B) p-value

Operative time (min):

- Range

$45-120$

$35-100$

- $\quad$ Mean \pm SD

$72.61 \pm 15.43$

$54.28 \pm 19.63$

$<0.001$

Blood loss (cc):

Mean \pm SD

$98.26 \pm 15.67$

$64.04 \pm 19.11$

$<0.001$

Hospital stay: (No, \%)

- Less than 2 days

0

$19(90.5 \%)$

- 2 - 4 days

$23(100 \%)$

$2(9.5 \%)$

$<0.001$

Intraoperative complications: (No, \%)

- Dural tear

$1(4.3 \%)$

$1(4.7 \%)$

- Root injury

0

- Soft tissues injury

0

0

- Vascular injury

0

0

Postoperative complications:

- CSF leak

0

0

- Neurological deficit

0

0

- Infection

0

0

- Hematoma

0

- Cage failure

0 
Table 3. Mean values of VAS and NDI after 1 year follow up.

\begin{tabular}{lccc}
\hline & ACDF (group A) Mean \pm SD & PCF (group B) Mean \pm SD & p-value \\
\hline VAS & & & \\
Pre op. & & & \\
Post op. & $3.57 \pm 0.85$ & $8.47 \pm 1.16$ & 0.88 \\
$-\quad$ First day & $3.21 \pm 0.99$ & $1.81 \pm 0.81$ & 0.01 \\
$-\quad$ 3 months & $0.91 \pm 0.33$ & $0.57 \pm 0.33$ & 0.02 \\
$-\quad$ 12 months & $0.47 \pm 0.13$ & $0.21 \pm 0.11$ & 0.03 \\
& & & \\
$\quad$ NDI & & & 0.18 \\
$\quad$ Pre op. & $47.48 \pm 17.02$ & $40.43 \pm 17.45$ & \\
$\quad$ Post op. & $41.11 \pm 14.36$ & $34.24 \pm 17.57$ & \\
$-\quad$ First day & $11.43 \pm 7.95$ & $5.57 \pm 2.11$ & \\
$-\quad 3$ months & $5.83 \pm 2.22$ & $2.87 \pm 1.62$ & \\
$-\quad$ 12 months & & & \\
\hline
\end{tabular}

\section{Discussion}

Cervical radiculopathy is common among middle aged and elderly patients. It produces upper limb pain, numbness, tingling and/or motor weakness. It is often caused by cervical disc herniation or foraminal stenosis by bone spurs. It can be treated by medications, physiotherapy, a variety of blocks and surgery. Persson et al. [1]; in their long term follow up study on cervical radiculopathy, showed that conservative management is equally effective to surgery. However, those patients who are refractory to conservative therapy are candidates for surgery.

Surgical treatment can be done either by anterior approach or posterior approach. Anterior cervical discectomy and fusion (ACDF) was considered the gold standard surgical line over the past decades. However, many disadvantages were recorded; including ventral approach related complications, instrumentation failure, pseudoarthrosis and adjacent disc degeneration [2].

Posterior cervical foraminotomy (PCF) was first reported by William [3] in 1983 and had success rate $96.5 \%$. Also, Henderson et al. [4] reported similar success rate in their study on 846 patients. Neither of them reported major complications nor cervical instability in comparison to ACDF and concluded that success rates are similar for the two approaches, and PCF has lower complication rates than ACDF. While other series as Korinth [5] study reported that PCF had lesser success rate than ACDF.

In spite of the conflicting outcomes on the success rates of PCF and ACDF, only few studies directly compare the results of both techniques. So we preformed this review to summarize the clinical, surgical and radiological outcomes of both procedures in treatment of cervical radiculopathy.

Our mean operative time was significantly shorter for PCF group (54 min) compared to ACDF group (72 $\mathrm{min})$. Also, Ruetten et al. [6], in his retrospective 
study on 175 patients, found the same results; where PCF mean operative time was 28 minutes and ACDF was 68 minutes. Rick Sasso et al. [7], stated that his mean time was 70 minutes for the fusion group, while Kim and Kim [8], reported 78.5 minutes for the percutaneous cervical foraminotomy. Our results can be explained by the shorter trajectory of PCF, with the absence of important anatomical structures that required meticulous dissection and the more time needed for adding instrumentation in ACDF.

In comparison with PCF, our mean intraoperative blood loss was lesser than ACDF (64 ml versus $98 \mathrm{ml}$ respectively). Similarly, Wen L et al. [9] found $261 \mathrm{ml}$ of blood loss in his study on 107 patients underwent ACDF, while Winder and Thomes [10] reported $96 \mathrm{ml}$ blood loss from PCF. Over all, there was a statistically significant difference between the two groups; favoring the PCF.

The mean complication rate in ACDF group was $7 \%$ and $4 \%$ in PCF group in most of the comparative studies [11]. These complications included ventral approach related complication as dysphagia, horsiness of voice, hematoma, esophageal injury and implant-related complications as pseudoarthrosis, adjacent segment degeneration, and wound infections and so on in ACDF patients. Root injury, CSF leak, infections and so on in PCF patients. There was no statistically significant difference in the complication rate between the two groups [11]. We recorded 2 cases of unintended dural tear in our study (one patient for each group), with no further postoperative CSF leak. Also, Hannallah et al. [12], showed $1 \%$ of dural tears after ACDF in their study, while Kwon [13] reported no complications after PCF in 33 patients. Fessler and Khoo [14], and Lawton et al. [15] reported 2 and 1 durotomies after PCF in 25 and 38 patients respectively. No other complications detected in our series.

As regards the postoperative hospital length of stay; most of our PCF group was discharged within 24 hours, but only 2 patients stayed for 4 days because of unintended dural tear in 1 patient and severe neck pain in the other patient, which decrease gradually with potent analgesics. But, all ACDF patients were discharged after 24 hours, this is similar to Paul et al. [16] and Winder and Thomas [10] who had a mean hospital stay 1.98 days after ACDF and 1.1 day after PCF respectively.

Although different clinical outcome criteria were measured in the studies comparing both procedures, satisfactory results of both approaches were reported. Success rate in ACDF group was 93.6\% - 96\% and PCF group was 75\% $100 \%$. No statistically significant difference was observed in these studies between the two groups [6] [17] [18] [19] [20].

Korinth et al. [5] reported that ACDF group had better outcome than the PCF group; with a significant difference ( $\mathrm{p}$-value $<0.05$ ). But, we reported a better clinical outcome regarding VAS and NDI; favoring PCF over ACDF with a significant difference in between as shown in Table 3. Similarly, Tumialan et al. [21] found that PCF patients were able to return to work and improve their quality of life significantly sooner than ACDF patients.

An assumed advantage of PCF over ACDF is the avoidance of fusion allowing 
for normal motion of spinal segment, and theoretically decreases adjacent level diseases. Although this remains a controversy; the reported rates of PCF adjacent segment disease seem to be less than that following ACDF [22] [23]. Herkowitz et al. [18] found a similar incidence of adjacent level disease for the two approaches. Caglar et al. [24], in their series of 84 patients underwent PCF reported one case of postoperative cervical kyphosis. This can be explained by Zdeblick et al. [25] biomechanical studies, which demonstrate the importance of preservation of the cervical facet in preventing iatrogenic instability.

Jogannathan et al. [26]; in a retrospective review of 162 patients treated by PCF with a follow up 77.3 months, showed no significant trend toward cervical kyphosis after PCF. In our series, no cases of adjacent level disease, cervical instability after PCF and re-operations were recorded during the period of follow up; this can be attributed to our short term of follow up.

\section{Conclusion}

Posterior cervical foraminotomy is a safe and effective technique for the treatment of cervical radiculopathy as compared to anterior cervical discectomy and fusion. PCF improves quality of life sooner relative to ACDF.

\section{Limitation and Recommendations}

The sample size is not large enough and the follow up period is short. Larger sample size and longer follow up period are needed.

\section{Conflicts of Interest}

The authors declare no conflicts of interest regarding the publication of this paper.

\section{References}

[1] Persson, L.C., Carlsson, C.A. and Carlsson, J.Y. (1997) Long-Lasting Cervical Radicular Pain Managed with Surgery, Physiotherapy or a Cervical Collar. A Prospective, Randomized Study. Spine, 22, 751-758. https://doi.org/10.1097/00007632-199704010-00007

[2] Fountas, K.N., kapsalaki, E.Z., Nikolakakos, L.G., et al. (2007) Anterior Cervical Discectomy and Fusion Associated Complications. Spine, 32, 2310-2317. https://doi.org/10.1097/BRS.0b013e318154c57e

[3] Williams, R.W. (1983) Micro Cervical Foraminotomy. A Surgical Alternative for Intractable Radicular Pain. Spine, 8, 708-716. https://doi.org/10.1097/00007632-198310000-00005

[4] Henderson, C.M., Hennessy, R.G., Shvey, H.M. and Shackelford, E.G. (1983) Posterior-Lateral Foraminotomy as an Exclusive Operative Technique for Cervical Radiculopathy: A Review of 846 Consecutively Operated Cases. Neurosurgery, 13, 504-512. https://doi.org/10.1227/00006123-198311000-00004

[5] Korinth, M.C., Kruger, A., Oertel, M.F. and Gilsbach, J.M. (2006) Posterior Foraminotomy or Anterior Discectomy with Polymethyl Methacrylate Interbody Stabilization for Cervical Soft Disc Disease: Results in 292 Patients with Monoradiculo- 
pathy. Spine, 31, 1207-1214. https://doi.org/10.1097/01.brs.0000217604.02663.59

[6] Ruetten, S., Komp, M., Merk, H. and Godolias, G. (2008) Full Endoscopic Cervical Posterior Foraminotomy for the Operation of Lateral Disc Herniations Using 5.9 mm Endoscopes: A Prospective, Randomized, Controlled Study. Spine, 33, 940-948. https://doi.org/10.1097/BRS.0b013e31816c8b67

[7] Sasso, R.C., Smucker, J.D., Hacker, R.J. and Heller, J.G. (2007) Artificial Disc versus Fusion: A Prospective, Randomized Study with 2 Years Follow Up on 99 Patients. Spine, 32, 2933-2940. https://doi.org/10.1016/j.spinee.2006.06.056

[8] Kim, K.T. and Kim, Y.B. (2009) Comparison between Open Procedure and Tubular Retractor Assisted Procedure for Cervical Radiculopathy: Results of a Randomized Controlled Study. Journal of Korean Medical Science, 24, 649-653. https://doi.org/10.3346/jkms.2009.24.4.649

[9] Wen, L., Jin, D., Xie, W., Li, Y., Chen, W., Zhang, S. and Jiang, X. (2018) Hidden Blood Loss in Anterior Cervical Fusion Surgery: An Analysis of Risk Factors. World Neurosurgery, 109, 625-629. https://doi.org/10.1016/j.wneu.2017.10.050

[10] Winder, M.J. and Thomas, K.C. (2011) Minimally Invasive versus Open Approach for Cervical Lamino Foraminotomy. Canadian Journal of Neurological Sciences, 38 , 262-267. https://doi.org/10.1017/S0317167100011446

[11] Liu, W.-J., Hu, L., Chov, P.-H., Wang, J.-W. and Kan, W.-S. (2016) Comparison of Anterior Cervical Discectomy and Fusion versus Posterior Cervical Foraminotomy in the Treatment of Cervical Radiculopathy: A Systematic Review. Orthopedic Surgery, 8, 425-431. https://doi.org/10.1111/os.12285

[12] Hannallah, D., Lee, J., Khan, M., Donaldson, W.F. and Kang, J.D. (2008) Cerebrospinal Fluid Leaks Following Cervical Spine Surgery. The Journal of Bone and Joint Surgery. American Volume, 90, 1101-1105. https://doi.org/10.2106/JBJS.F.01114

[13] Kwon, Y.J. (2014) Long Term Clinical and Radiologic Outcomes of Minimally Invasive Posterior Cervical Foraminotomy. Journal of Korean Neurosurgical Society, 56, 224-229. https://doi.org/10.3340/jkns.2014.56.3.224

[14] Fessler, R.G. and Khoo, L.T. (2002) Minimally Invasive Cervical Micro Endoscopic Foraminotomy: An Initial Clinical Experience. Neurosurgery, 51, S37-S45. https://doi.org/10.1097/00006123-200211002-00006

[15] Lawton, C.D., Smith, Z.A., Lam, S.K., Habib, A., Wong, R.H. and Fessler, R.G. (2014) Clinical Outcomes of Micro Endoscopic Foraminotomy and Decompression in the Cervical Spine. World Neurosurgery, 81, 422-427. https://doi.org/10.1016/j.wneu.2012.12.008

[16] Arnold, P.M., Rice, L.R., Anderson, K.K., Mcmahon, J.K., Connelly, L.M. and Norvell, D.C. (2011) Factors Affecting Hospital Length of Stay Following Anterior Cervical Discectomy and Fusion. Evidence-Based Spine-Care Journal, 2, 11-18. https://doi.org/10.1055/s-0030-1267108

[17] Selvanathan, S.K., Beagrie, C., Thomson, S., et al. (2015) Anterior Cervical Discectomy and Fusion versus Posterior Cervical Foraminotomy in the Treatment of Brachialgia: The Leeds Spinal Unit Experience (2008-2013). Acta Neurochirurgica, 157, 1595-1600. https://doi.org/10.1007/s00701-015-2491-8

[18] Herkowitz, H.N., Kurz, L.T. and Overhold, D.P. (1990) Surgical Management of Cervical Soft Disc Herniation. A Comparison between the Anterior and Posterior Approach. Spine, 15, 1026-1030. https://doi.org/10.1097/00007632-199010000-00009

[19] Wirth, F.P., Dowd, G.C., Sanders, H.F. and Wirth, C. (2000) Cervical Discectomy. A Prospective Analysis of Three Operative Techniques. Surgical Neurology, 53, 340-346. 
https://doi.org/10.1016/S0090-3019(00)00201-9

[20] Alvin, M.D., Lubelski, D., Abdullah, K.G., Whitemore, R.G., Benzel, E.C. and Mroz, T.E. (2016) Cost-Utility Analysis of Anterior Cervical Discectomy and Fusion with Plating (ACDFP) versus Posterior Cervical Foraminotomy (pcf) for Patients with Single Level Cervical Radiculopathy at 1 Year Follow Up. Clinical Spine Surgery, 29, E67-E72. https://doi.org/10.1097/BSD.0000000000000099

[21] Tumialan, L.M., Ponton, R.P. and Gluf, W.M. (2010) Management of Unilateral Cervical Radiculopathy in the Military: The Cost Effectiveness of Posterior Cervical Foraminotomy Compared with Anterior Cervical Discectomy and Fusion. Neurosurgical Focus, 28, E17. https://doi.org/10.3171/2010.1.FOCUS09305

[22] Hilibrand, A.S., Carlson, G.D., Palumbo, M.A., et al. (1999) Radiculopathy and Myelopathy at Segments Adjacent to the Site of a Previous Anterior Cervical Arthrodesis. The Journal of Bone and Joint Surgery. American Volume, 81, 519-528. https://doi.org/10.2106/00004623-199904000-00009

[23] Clarke, M.J., Ecker, R.D., Krauss, W.E., et al. (2007) Same Segment and Adjacent Segment Disease Following Posterior Cervical Foraminotomy. Journal of Neurosurgery Spine, 6, 5-9. https://doi.org/10.3171/spi.2007.6.1.2

[24] Caglar, Y.S., Bozkurt, M., Kahilogullari, G., et al. (2007) Keyhole Approach for Posterior Cervical Discectomy: Experience on 84 Patients. Minimally Invasive Neurosurgery, 50, 7-11. https://doi.org/10.1055/s-2007-970138

[25] Zdeblick, T.A., Zou, D., Warden, K.E., et al. (1992) Cervical Stability after Foraminotomy. A Biomechanical in Vitro Analysis. The Journal of Bone and Joint Surgery. American Volume, 74, 22-27. https://doi.org/10.2106/00004623-199274010-00004

[26] Jagannathan, J., Sherman, J.H., Szabo, T., et al. (2009) The Posterior Cervical Foraminotomy in the Treatment of Cervical Disc/Osteophyte Disease: A Single-Surgeon Experience with a Minimum of 5 Years Clinical and Radiographic Follow up. Journal of Neurosurgery Spine, 10, 347-356.

https://doi.org/10.3171/2008.12.SPINE08576 